\title{
SECULARIZAÇÃO E \\ AUTONOMIA DO DIREITO EM HOBBES
}

SECULARIZATION AND AUTONOMY OF LAW IN HOBBES

SECULARIZACIÓN Y AUTONOMÍA DEL DERECHO EN HOBBES

Draiton Gonzaga de Souza ${ }^{1}$

Luis Rosenfield ${ }^{2}$

Resumo: O nascimento do positivismo jurídico hobbesiano gerou mudanças paradigmáticas na estrutura do direito - agora secularizado e monopolizado pelo Estado -, impondo uma nova estrutura epistemológica do direito e da ciência jurídica. Nesse momento histórico, o direito posto pelo Estado passa a se apresentar como única fonte legislativa, enquanto a normatização religiosa deixa de ter importância. O presente artigo busca analisar de que forma o processo de secularização e trânsito para a modernidade no pensamento de Hobbes influencia os desenvolvimentos posterior no plano do constitucionalismo. Para tanto, são analisadas criticamente as contribuições de Hobbes para a evolução do direito constitucional - na perspectiva do reforço da autoridade soberana e da competência normativa do soberano -, no plano do positi-vismo jurídico. A justificação da presente pesquisa se estabelece pela influência decisiva

1 Pós-doutorado na Universidade de Kassel (Alemanha). Professor dos PPGs em Filosofia e Direito da PUCRS. E-mail: draiton@pucrs.br.

2 Mestrando em Direito (IMED). Bolsista da CAPES. Membro do KATHÁRSIS - Centro de Estudos em Direito e Literatura da IMED. Secretário Executivo da Rede Brasileira Direito e Literatura (RDL). Editor-assistente da ANAMORPHOSIS - Revista Internacional de Direito e Literatura. E-mail: luis.rosenfield@gmail.com. 
que a teoria hobbesiano ainda possui no que se refere aos princípios fundadores das democracias seculares contemporâneas.

Palavras-chave: Hobbes. Leviatã. Behemoth. Positivismo Jurídico. Secularização.

Abstract: The birth of Hobbesian legal positivism generated paradigmatic changes in the structure of law - now secularized and monopolized by the State - imposing a new epistemological framework of law and legal science. In this historical moment, the law created by the State is the only source of law, while religious normativity ceases to be relevant. This article analyzes how the process of secularization and the transit to modernity in the thought of Hobbes influences the subsequent developments of modern constitutionalism. For this purpose, it critically analyzes the contributions of Hobbes to the evolution of constitutional law - from a perspective of strengthening the sovereign authority and the legislative powers of the sovereign - within legal positivism. The justification for this research is the decisive influence that Hobbesian theory still has over the founding principles of contemporary secular democracies.

Keywords: Hobbes. Leviathan. Behemoth. Legal positivismo. Secularization.

Resumen: El nacimiento del positivismo jurídico hobbesiano generó cambios paradigmáticos en la estructura del Derecho - ahora secularizado y monopolizado por el Estado -, imponiendo una nueva estructura epistemológica del Derecho y de la Ciencia Jurídica. En ese momento histórico, el Derecho puesto por el Estado pasa a presentarse como única fuente legislativa, mientras que la normatización religiosa deja de tener importancia. El presente artículo busca analizar de qué forma el proceso de secularización y tránsito hacia la modernidad en el pensamiento de Hobbes influye sobre los desenvolvimientos posteriores en el plano del constitucionalismo. Para ello se analizan críticamente las contribuciones de Hobbes a la evolución del derecho constitucional - desde la perspectiva del refuerzo de la autoridad soberana y de la com- 
petencia normativa del soberano -, en el plano del positivismo jurídico. La justificación de la presente investigación se establece por la influencia decisiva que la teoría hobbesiana aún posee en lo que se refiere a los principios fundadores de las democracias seculares contemporáneas.

Palabras clave: Hobbes. Leviatán. Behemoth. Positivismo Jurídico. Secularización.

\section{INTRODUÇÃO}

\section{noção de secularização é a principal porta de entrada para se falar
em autonomia do Direito em uma perspectiva histórica. Não se
trata aqui de traçar um panorama exaustivo do que se entende por} secularização - o que seria tarefa da Begriffsgeschichte -, mas apenas de indicar os fundamentos metodológicos básicos necessários para tratar o tema com rigor científico. Delinear um conceito consistente e satisfatório do que vem a ser secularização é tarefa árdua devido ao fato de esse conceito polissêmico ter sofrido intensa metamorfose semântica nos últimos duzentos anos. No presente artigo, num primeiro momento, expõe-se esse conceito-chave de interpretação do período moderno do pensamento Ocidental. Apresentada essa plataforma hermenêutica, procura-se indicar como Thomas Hobbes funda seu pensamento em bases seculares.

\section{SECULARIZAÇÃO E TRÂNSITO PARA A MODERNIDADE}

Secularização é a tradução da palavra latina saecularisatio ${ }^{3}$, que remonta a saeculum (que já aparece na tradução latina de São Jerônimo, a Vulgata); em português, "século" (éon, em grego) significa tanto um período de cem anos como "este tempo" e, por extensão, mundo; saeculum aparece como sinônimo "deste

3 Ver, para tanto, o verbete aion (éon) no Theologisches Begriffslexikon zum Neuen Testament. Neukirchen: Neukirchener Verlag, 2005. 
mundo" em trechos neotestamentários (ver Mt 13,22 e Mc 4,19: "a preocupação do mundo" - he mérima tou aionos). Em Mt 12, 32, verifica-se a contraposição entre "este" e o "futuro" mundo ("nem neste mundo, nem no vindouro").

Saecularisatio foi utilizada pela primeira vez no contexto jurídico ${ }^{4}$ (jurídicocanônico e jurídico-político): 1. no campo jurídico-canônico, aparece a palavra saecularisatio no Codex luris Canonici, quando trata da passagem (transferência) do estado de "regular" (ordens religiosas) para "secular", isto é, quando um monge abandona o mosteiro e vai viver como "secular" (veja-se a expressão "padre secular"). Também se usa o termo para designar o presbítero que abandona o exercício do sacerdócio e se laiciza, se seculariza; 2. no âmbito jurídico-político, a palavra secularização é utilizada como sinônima de desapropriação, isto é, quando determinados bens passaram da Igreja para o Estado, como ocorre, por exemplo, no século XIX, na Alemanha. Em ambos os casos, está presente a ideia de passagem, de trânsito de um estado para o outro; no segundo caso, vê-se, claramente, a troca de titularidade de certos bens, que passam do poder espiritual para o poder temporal, isto é, uma passagem do teológico ao antropológico, do transcendente ao imanente, do eterno ao passageiro, do divino ao humano, do céu à terra, do além ao aquém, do sagrado ao profano, da civitas Dei à civitas terrena.

Além dos significados de secularização supramencionados, Hans Joas ${ }^{5}$ acrescenta outros: a secularização como genealogia da cultura moderna em relação à tradição judaico-cristã, tanto numa visão crítica (negativa) como numa visão afirmativa; menciona também três conceitos procedentes das ciências sociais: a diminuição da influência da religião ${ }^{6}$, a redução da religião à esfera privada e a autonomização de âmbitos sociais que se desprendem do controle religioso.

4 Para uma exposição pormenorizada desse processo, ver MARRAMAO, Giacomo. Céu e terra: genealogia da secularização. Tradução de Guilherme Alberto Gomez de Andrade. São Paulo: Fundação Editora da UNESP, 1997.

5 JOAS, Hans. Die säkulare Option. Ihr Aufstieg und ihre Folgen [A opção secular. Sua ascensão e suas consequências]. Deutsche Zeitschrift für Philosophie. Berlin: Akademie Verlag, 2009. p. 293.

6 TAYLOR, Charles. Uma era secular. Traduzido por Luzia Araújo e Nelio Schneider São Leopoldo: Editora UNISINOS, 2010. p. 15. Taylor afirma: "Nesse segundo sentido, a secularidade consiste no abandono de convicções e práticas religiosas, em pessoas se afastando de Deus e não mais frequentando a igreja". 
Destaque-se, ainda, uma acepção de secularização que Hans Joas encontra na obra de Charles Taylor, ao tratar da mudança das condições de vida em sociedade - para todos e, desse modo, também para os crentes -, oriundas do surgimento da possibilidade da descrença; aqui está o que Charles Taylor chama de "opção secular": "na passagem de uma sociedade em que a fé em Deus é inquestionável e, de fato, não problemática, para uma na qual a fé é entendida como uma opção entre as outras e, em geral, não a mais fácil de ser abraçada"7.

Ressalte-se que o conceito "secularização" não é unívoco, mas multifacetado e passível de muitas interpretações, como destaca Henrique Cláudio de Lima Vaz, quando afirma haver:

(...) formas de avaliação do novo na modernidade que dão primazia à tradição teológica e julgam descobrir na novidade moderna a permanência de categorias teológicas transformadas com relação ao seu sentido original. Sobretudo três dessas interpretações alcançaram notoriedade entre os estudiosos 8 .

Nesse contexto, aponta algumas leituras possíveis: a leitura política (Carl Schmitt ${ }^{9}$ ); a leitura historicista (Karl Löwith ${ }^{10}$ ), numa perspectiva escatológica ${ }^{11}$; e a leitura teológico-metafísica (Eric Voegelin ${ }^{12}$ ).

Porém esse tipo de interpretação do surgimento da modernidade é contestado por autores que pensam que "a novidade moderna irrompe como algo jamais

7 TAYLOR, Charles. Uma era secular. Traduzido por Luzia Araújo e Nelio Schneider São Leopoldo: Editora UNISINOS, 2010. p. 15. À palavra secularização são comumente associados os seguintes termos: descristianização, dessacralização, desencantamento, desmitologização, desdivinização, imanentização, antropologização, mundanização, laicização, desapropriação, expropriação. Não se entrará aqui na discussão sobre a relação entre secularização e essas significações, pois isso ultrapassaria muito o âmbito do presente trabalho.

8 LIMA VAZ, Henrique Cláudio de. As raízes da modernidade. São Paulo: Loyola, 2002. p. 20.

9 SCHMITT, Carl. Politische Theologie. Vier Kapitel zur Lehre von der Souveranität.

10 LÖWITH, Karl. Weltgeschichte und Heilsgeschehen [História do mundo e acontecimento salvífico].

11 Ver o excelente livro de Walter Jaeschke sobre a questão da escatologia JAESCHKE, Walter. Die Suche nach den eschatologischen Wurzeln der Geschichtsphilosophie. Eine historische Kritik der Säkularisierungsthese, München, 1976; JAESCHKE, Walter. Säkularisierung. In: Handbuch religionswissenschaftlicher Grundbegriffe. Bd. 5, Stuttgart: Kohlhammer, 2001. p. 9-20.

12 VOEGELIN, Eric. Ordem e História (5 v.). São Paulo: Loyola, 2009. Ver também VOEGELIN, Eric. A nova Ciência da Política. Brasília: Editora da UNB, 1979. 
acontecido na história passada da humanidade"13; aqui "o novo se manifesta como index sui, dotado de uma evidência intrínseca que não necessita justificarse diante do antigo"14. Como representantes dessa posição, mencionem-se Marcel Gauchet ${ }^{15}$ e Hans Blumenberg, os quais, em sua obra Legimität der Neuzeit [Legitimidade da modernidade], como o título já indica, advoga uma legitimidade desse período, despotencializando elementos de herança cristã ${ }^{16}$.

Não obstante as objeções de Gauchet e Blumenberg, defende-se aqui que, com a supressão do elemento teológico, os atributos do Deus judaico-cristão não desapareceram, mas apenas trocaram de titular: não mais Deus, mas sim o homem (seja coletiva seja individualmente) assumirá os predicados da divindade, ainda que essa não seja mencionada. Por isso, considera-se imperioso concordar com Carl Schmitt, quando afirma, com muita propriedade, em sua Teologia Política que: "Todos os conceitos centrais da teoria moderna do Estado são conceitos teológicos secularizados"17, incluindo-se no rol desses conceitos a noção de soberania. Possivelmente essa seja uma das descrições mais precisas para definir o significado de secularização no âmbito jurídico, uma vez que o Estado de Direito moderno se afirmou a partir do deísmo, contraposto, portanto, ao teísmo ${ }^{18}$. A categoria de secularização estabelece a chave da metamorfose histórica e da própria estrutura sistêmica dos conceitos jurídicos, na medida em que

13 LIMA VAZ, Henrique Cláudio de. As raízes da modernidade. São Paulo: Loyola, 2002. p. 23.

14 LIMA VAZ, Henrique Cláudio de. As raízes da modernidade. São Paulo: Loyola, 2002. p. 24.

15 Ver especialmente GAUCHET, Michel. Le désenchantement du monde: une histoire politique de la religion. Paris: Gallimard, 1985.

16 Sobre essa problemática, digno de nota é um projeto italiano-alemão, cujos trabalhos encontram-se reunidos no volume: Christentum, Säkularisation und modernes Recht (Cristianesimo, Secolarizzazione e diritto moderno). Org. por L. Lombardi VALLAURI e G. DILCHER. Baden-Baden; Milão, 1981 (1527p., em dois volumes, contendo trabalhos de autores como Michel Villey, Winfried Hassemer, Helmut Coing e o trabalho de Ilse Staff com o título "Zum Begriff der politischen Theologie bei Carl Schmitt" (Sobre o conceito de Teologia Política em Carl Schmitt). O livro apresenta as seguintes secções: conceitos gerais, direito público, direito civil, direito penal e uma perspectiva sociológica. Foi publicado um volume, contendo apenas os trabalhos publicados em alemão: Christentum und modernes Recht [Cristianismo e direito moderno], com o subtítulo: "Contribuições para o problema da secularização".

17 No original: "Alle prägnanten Begriffe der modernen Staatslehre sind säkularisierte theologische Begriffe" (SCHMITT, Carl. Politische Theologie, p. 49).

18 SCHMITT, Carl. Teología política. Tradução de Francisco Javier Conde. Madrid: Editorial Trotta, 2009. p. 37. 
o direito estatal os extrairia diretamente do plano teológico. Esse procedimento de translação conceitual adquiriria características emblemáticas com a evolução da teoria da soberania, desde a fase absolutista até a democrático-popular ${ }^{19}$.

Portanto, descurar esse elemento é desconhecer a gênese de uma série de categorias que, na contemporaneidade, aparecem como se não tivessem nenhuma relação com a Teologia. Para o jurista alemão Ernst-Wolfgang Böckenförde, no mesmo diapasão de Carl Schmitt, "o estado secularizado, livre, vive de pressupostos que ele mesmo não pode garantir"20 e é o resultado do processo de secularização, o que é corroborado por Berman, ao asseverar que "instituições, conceitos e valores básicos dos sistemas jurídicos ocidentais têm suas origens em rituais religiosos, liturgias e doutrinas dos séculos XI e XII (...) A Ciência Jurídica Ocidental é uma teologia secular, que por vezes não faz sentido porque seus pressupostos teológicos não são mais aceitos"21.

Enfatize-se que a secularização ultrapassará significantemente a sua acepção inicial: segundo Habermas, "a palavra 'secularização' teve, a princípio, o significado jurídico de uma transferência compulsória dos bens da Igreja para o poder público secular. Esse significado foi transmutado para o surgimento da modernidade cultural e social como um todo"22. A secularização, por meio dessa ampliação de significado, alcança o status de categoria genealógica da modernidade, capaz de sintetizar o desenvolvimento histórico da civilização ocidental na sua relação com a tradição judaico-cristã. As interpretações que podem ser dadas ao termo secularização mudaram consideravelmente com o passar do tempo, como visto anteriormente. É possível, ainda, relacionar esse processo com a descristianização (ruptura com os princípios cristãos) e com a dessacralização (e consequente

19 MARRAMAO, Giacomo. Céu e terra: genealogia da secularização. Tradução de Guilherme Alberto Gomez de Andrade. São Paulo: Fundação Editora da UNESP, 1997. p. 57.

20 BÖCKENFÖRDE, Ernst-Wolfgang. Recht, Staat, Freiheit: Studien zur Rechtsphilosophie, Staatstheorie und Verfassungsgeschichte [Direito, Estado, liberdade: estudos sobre a filosofia do direito, teoria do Estado e história da constituição]. Frankfurt am Main: Suhrkamp, 2006. p. 43-72. No original: "Der freiheitliche, säkularisierte Staat lebt von Voraussetzungen, die er selbst nicht garantieren kann". Cf. Der säkularisierte Staat: sein Charakter, seine Rechtfertigung und seine Probleme im 21. Jahrhundert. München: Carl-Friedrich-vonSiemens-Stiftung, 2007, p. 43-72.

21 BERMAN, Harold J. Direito e revolução. A formação da tradição jurídica ocidental. São Leopoldo: Editora da Unisinos, 2004, p. 212.

22 HABERMAS, Jürgen. Fé e saber. São Paulo: Editora Unesp, 2013, p. 5. 
transferência desse conteúdo sagrado para o Estado e seus rituais) ${ }^{23}$.

Os duradouros embates entre Império e Papado (1057-1122) contribuíram para que os poderes temporais se tornassem conscientes de sua própria autonomia. Os estados nascentes começaram a perceber e a vislumbrar a irredutível secularidade da política e dos fundamentos terrenos da soberania estatal2 ${ }^{24}$. Segundo Marc Bloch, é inadequado procurar uma leitura linear sobre secularização, em razão do caráter paradoxal que possui o longo processo de intercâmbio entre Igreja e Estado. A situação de conflito e complementação entre poder eclesiástico e poder secular redunda em um jogo de espelhos: enquanto a Igreja procura se estabilizar e se afirmar como uma instituição centralizadora e de racionalização burocrática, o Estado começa a desenvolver características sacrais e a ritualizar seus próprios procedimentos ${ }^{25}$.

A partir do século XVIII, a secularização adquire uma dimensão históricofilosófica. Ou seja, a doutrina dos dois reinos é substituída pela história e pelo tempo histórico, que passa a ser invocado como fonte última de justificação para os planejamentos políticos e para a organização social. Nesse contexto, pode-se falar de uma autonomização da realidade temporal, segundo a qual a vida hic et nunc consiste no nómos orientador por si mesmo (autós, autonomia) e não por outrem (héteros, heteronomia). A secularização torna-se, para Koselleck, uma categoria essencialmente ligada ao conceito unitário de tempo histórico, razão pela qual considera que o termo mais adequado para designar esse processo seria temporalização ${ }^{26}$.

Giacomo Marramao aponta que o termo secularização adquire uma formatação histórica inequívoca, quando um delegado francês, durante as negociações para a Paz da Westphalia (1646), utilizou a palavra séculariser para assinalar a passagem de propriedades religiosas para mãos seculares, ou seja, para indicar a expropriação

23 MARRAMAO, Giacomo. Céu e terra: genealogia da secularização. Tradução de Guilherme Alberto Gomez de Andrade. São Paulo: Fundação Editora da UNESP, 1997. p. 16.

24 MARRAMAO, Giacomo. Céu e terra: genealogia da secularização. Tradução de Guilherme Alberto Gomez de Andrade. São Paulo: Fundação Editora da UNESP, 1997. p. 22.

$25 \mathrm{BLOCH}$, Marc. Os reis taumaturgos. O poder sobrenatural do poder régio. França e Inglaterra. São Paulo Companhia das Letras, 1993. p. 76-95.

26 KOSELLECK, Reinhart. Estratos do tempo: estudos sobre história. Tradução de Markus Hediger. 1. ed. Rio de Janeiro: Contraponto/PUC-Rio, 2014. p. 168-175. 
dos bens eclesiásticos em favor dos príncipes ou das Igrejas nacionais reformadas ${ }^{27}$. Nesse contexto, a expressão remete ao gradual avanço das ambições do Estado moderno - nascido depois da Paz da Westphalia, de 1648 -, que já indicava uma pretensão de monopólio sobre a questão do domínio temporal. Essa expulsão da autoridade eclesiástica das questões não espirituais está intimamente relacionada, portanto, com o lento e tormentoso processo de afirmação de uma jurisdição secular, fundada em principais laicos e sob a égide do Estado, em um território da vida social que se encontrava sob controle da Igreja ${ }^{28}$.

Em um primeiro momento da história europeia, não se trata de secularizar apenas a estrutura eclesiástica, mas sim de um longo processo de mudança de consciência religiosa, que se poderia chamar de secularização do individualismo religioso. Isso não significa que o indivíduo não possua convicções religiosas, mas que essas repousam especialmente em sua esfera individual, em sua vida privada. Essa noção de emancipação dos indivíduos por meio de um individualismo religioso seria, para Troeltsch, um traço distintivo do protestantismo de sua época. A cultura moderna, nas palavras do teólogo alemão, está marcada pela busca de ideais forjados de maneira autônoma: essa autonomia teria como finalidade contrapor-se à autoridade eclesiástica. E a validade e a legitimidade dessa razão autônoma e secularizada dependeriam de sua força de persuasão e convencimento para exercer sua influência ${ }^{29}$.

Pode-se encontrar no trânsito para a modernidade, momento compreendido, em rasgos gerais, entre os séculos XV e XVIII, os alicerces para o que é possível identificar como Estado de Direito. Nessa época, surge a necessidade de consolidação do princípio da tolerância como forma de dar fim às guerras

27 MARRAMAO, Giacomo. Céu e terra: genealogia da secularização. Tradução de Guilherme Alberto Gomez de Andrade. São Paulo: Fundação Editora da UNESP, 1997. p. 16-17.

28 MARRAMAO, Giacomo. Céu e terra: genealogia da secularização. Tradução de Guilherme Alberto Gomez de Andrade. São Paulo: Fundação Editora da UNESP, 1997. p. 19. Após a celebração da Paz da Westphalia, na segunda metade do século XVII, quando do final das hostilidades oriundas das guerras confessionais, dá-se fim ao profundo derramamento de sangue que assolou o continente europeu. Isso significou, em termos jurídicos, a destruição do ideal universalista da respublica chistiana, fundada conúbio entre Céu (auctoritas pontifícia) e Terra (potestas imperial). Em síntese, a Igreja perde a maior parte de seu poder político, somando-se ao fato de que os Estados seculares se veem livres das responsabilidades tradicionalmente impostas pela esfera religiosa.

29 TROELTSCH, Ernst. Protestantisme et modernité. Tradução de Marc B. de Launay. Paris: Éditions Gallimard, 1991. p. 
confessionais que assolavam a Europa. É possível afirmar com segurança que uma das primeiras dimensões, senão a primeira, dos direitos humanos encontra-se no reconhecimento da liberdade religiosa e da tolerância. A ruptura estabelecida pela liberdade religiosa desempenha o papel-chave de sustentáculo para os avanços do Iluminismo, numa gradual consolidação dos princípios seculares ${ }^{30}$.

Por fim, mencione-se que, no debate com Schmitt em meados do século $X X$, em uma avaliação epistolar sobre o desenrolar dos eventos das décadas de vinte, trinta e quarenta, Hans Blumenberg reafirma que a natureza paradoxal é agravada pelo caráter permanente ainda não moderno da modernidade. Para o filósofo, a secularização não exprime apenas o simples processo de dissolução da religião tradicional. Sua evolução denota a transformação da hierarquia de valores nas diversas ideologias institucionais da modernidade. A secularização, então, funcionaria como fator de estranhamento das nascentes instituições de estado no plano da temporalidade. Nas reflexões entre Schmitt e Blumenberg surgem indícios que configuram, em certo sentido, uma secularização não cumprida, débil em sua pretensa superação da ordem religiosa ${ }^{31}$.

\section{THOMAS HOBBES: A NASCENTE AUTONOMIA DO DIREITO NO ESTADO ABSOLUTISTA, SOBERANO E SECULAR}

Por meio de sua principal obra, o Leviatã (1651), Thomas Hobbes inaugura o positivismo jurídico e a teoria política moderna. A célebre figura do soberano na capa da primeira edição do Leviatã - entidade meio-homem, meio-deus, que domina o país com a espada e o cetro - simboliza o nascimento da República. Os fortes simbolismos ali contidos significam a união entre o poder temporal e o poder espiritual. Com essa filosofia política fundada na soberania, consagra-se a figura do poder soberano ilimitado que emana autoridade aos confins mais distantes do Estado. Para Hobbes, a alternativa do poder uno e

30 MARTÍNEZ, Gregório Peces-Barba. Trânsito a la modernidad y derechos fundamentales. In: MARTÍNEZ, Gregório Peces-Barca; GARCIA, Eusebio Fernandez. História de los derechos fundamentales. T. I. Transito a la modernidad. Siglos XVI y XVII. Madrid: Dykinson, 2003. p. 29-88.

31 BLUMENBERG, Hans; SCHMITT, Carl. L'enigma della modernità. Roma-Bari: Laterza, 2012. p. 4-18. 
indivisível do soberano é o único meio para manutenção da paz, evitando-se assim a guerra civil ${ }^{32}$.

A construção positivista de Hobbes determina que somente pode ser direito aquilo que é emanado pelo Estado (Auctoritas non veritas facit legem). A centralidade do estado em sua filosofia política é determinada pelo monopólio da produção do direito e da soberania. Sua contribuição influenciou de modo decisivo o que viria a ser a teoria do estado séculos mais tarde. As estruturas políticas da modernidade, esboçadas pela filosofia política secularizada de Hobbes, são elementos sólidos para compreender o atual estágio da civilização Ocidental.

Sua visão conservadora sobre a origem, o papel e a finalidade do poder soberano ilimitado - e, portanto, da relevância da autoridade em detrimento da liberdade - fez com que o filósofo inglês antecipasse pragmaticamente o nascimento dos grandes estados modernos. Ainda hoje, é nítida a marca dos antigos conceitos hobbesianos de autoridade, ordem e unidade em todas democracias seculares contemporâneas ${ }^{33}$.

A principal e recorrente obsessão de Hobbes concentra-se na guerra de todos contra os todos (bellum omnium contra omnes). Sua teoria política é arquitetada de modo a evitar a implosão das estruturas do Estado por meio de combates intestinais no seio da sociedade civil, que representa o pior dos males. Por essa razão, constrói um conceito de soberania centrado no poder soberano absoluto. Hobbes afirma, com veemência, que o soberano possui dois poderes principais: o de espada da justiça e o de espada da guerra. Para efetivamente poderem golpear seus adversários, as espadas devem estar na mão da mesma pessoa. Portanto, além de o soberano ter de segurar as duas espadas ao mesmo tempo, a balança da Justiça também deve estar sob seu absoluto controle ${ }^{34}$.

32 OST, François; KERCHOVE, Michel van de. De la pyramide au réseau? Pour un théorie dialectique du droit. Bruxelas: Publications des Facultés Universitaires Saint-Louis, 2002. p. 7.

33 BOBBIO, Norberto. Thomas Hobbes. Tradução de Carlos Nélson Coutinho. Rio de Janeiro: Campus, 1991. p. 27 e 56-60.

34 HOBBES, Thomas. Leviatã ou Matéria, forma e poder de um estado eclesiástico e civil. Tradução de João Paulo Monteiro e Maria Beatriz Nizza da Silva. 3. ed. São Paulo: Abril Cultural, 1983. p. 108-109. 
Na prática, a construção dessa simbologia política significava tolher o poder do Parlamento inglês e do judiciário da common law inglesa da época. Sua filosofia possui um referencial fático nas guerras civis que assolavam a Inglaterra do século XVII ${ }^{35}$. O filósofo foi testemunha ocular dessas guerras, levando-o a elaborar um sistema capaz de deter a desordem e a anarquia. Por essa razão, somente um poder uno, irrevogável e indivisível seria suficiente para combater esse processo ${ }^{36}$.

O mundo é definido entre dois polos extremos em que Behemoth e Leviatã coexistem. O Leviatã encarna a representação mitológica da ordem soberana da Common-wealth inglesa, enquanto o Behemoth representa a alegoria de "condição de possibilidade" para irrupção da guerra intestina. Para Hobbes, o Behemoth - também chamado de Longo Parlamento - equivale à falta de união da população, tornando o povo da nação em mera multidão dissolvida e pulverizada. O Longo Parlamento, então, significa a ascensão do dissenso no seio da sociedade, deixando de existir a aclamação e, consequentente, a legitimação do soberano ${ }^{37}$. Janine Ribeiro sintetiza a relação entre as figuras bíblicas do Leviatã e do Behemoth da seguinte forma:

35 WOOTTON, David. Divine right and democracy. An anthology of political writings in Stuart England. London: Penguis Classics, 1986. p. 8-16. Segundo o autor, "The seventeenth century was England's 'century of revolution'. The revolution of 1642-9, wich culminated in the execution of the king and the declaration of a republic, saw the formation of the first secular political party defending the inalienable rights of man, the Levellers. It gave rise to the first communist movement with a strategy for effective social action, the Diggers. And it led to the formulation of the first materialist theory of historical change, in the writings os James Harrington. The arguments of the American, the French and even the Russina revolutions can be traced back to the debates during England's mid-century crisis, while the arguments of the radicals were directed againt moderate defences of tradition and royalists defences of authority that were to provide the foundations on wich Hume and Burke could construct modern conservatism".

36 BOBBIO, Norberto. Thomas Hobbes. Tradução de Carlos Nélson Coutinho. Rio de Janeiro: Campus, 1991. p. 27. Analisar e contextualizar o momento histórico peculiar em que Hobbes estava inserido é vital para devida compreensão de sua obra. Em um período de forte efervescência política, Hobbes tentou traçar as bases para paz social. A gênese do movimento comunista, por exemplo, é fruto desse período histórico. Segundo Wootton, os argumentos contidos na Revolução Francesa, na Revolução Russa e na Revolução Americana podem ser rastreados até se chegar aos debates que tomam lugar na Inglaterra anos antes. Os movimentos que buscavam mudanças sociais ganham corpo e densidade a partir de revoltas como a dos Diggers e dos Levellers, sendo definidas como as primeiras formas de materialismo histórico (the first materialist theory of social change). Nesse sentido, ver WOOTTON, David. Divine right and democracy. An anthology of political writings in Stuart England. London: Penguis Classics, 1986. p. 8-16.

37 HOBBES, Thomas. Behemoth. Madrid: Tecnos, 2013. 
Pois o mesmo filósofo que censura as metáforas, por enganosas, enquadrou a sua obra com duas poderosas imagens bíblicas, as do Leviatã e do Beemot, um o monstro que reina sobre as criaturas do orgulho (nós: os homens) e pelo terror nos pacifica, e o outro, monstro do caos, da guerra civil, do Longo Parlamento ${ }^{38}$.

Nesse mesmo sentido, existe um interessante paralelo entre a guerra civil e o estado de natureza: para Agamben, quando a guerra civil se esgota, essa multidão dissolvida e pulverizada passa a ser uma multidão desunida. A desunião significa a volta ao estado de natureza, que Hobbes tão insistentemente teoriza. Dessa forma, a guerra civil equivale à projeção do estado de natureza dentro da cidade, da urbe ${ }^{39}$.

Importante destacar que, na tradição cristã, a figura do Leviatã era vista com uma forte conotação demoníaca. Para muitos teólogos, o Leviatã era descrito como o "Homem da Anomia", associado diretamente à figura do Anticristo. Assim, o que define essencialmente a teoria Hobbes é a divisão - no plano da autonomia - entre o Reino de Deus (regnum Dei) e o Reino profano (regnum hominum). A metáfora do Leviatã caracteriza a devida ordem no mundo dos homens no Reino Profano, não mais divinizado ${ }^{40}$.

Hobbes certamente não desconhecia essa relação. As ilações apresentadas pelo filósofo inglês inclusive lhe custariam muito caro anos mais tarde, perseguido por setores religiosos - de diversas orientações políticas - do establishment inglês. Ao mesmo tempo em que a paz seria estabelecida na terra pelo Estado - e, em grande medida, pelo direito positivo secularizado posto pelo Estado -, as ideias profético-religiosas impregnariam e interpenetrariam sua filosofia política ${ }^{41}$.

Diante do cenário de medo da dissolução do Estado, sempre iminente, Hobbes propõe um contrato entre o povo e o monarca absolutista, entre os súditos e o soberano fiador da paz social. Sua visão do contratualismo o tornou o primeiro

38 RIBEIRO, Renato Janine. Ao leitor sem medo. Hobbes escrevendo contra o seu tempo. $2^{a}$ ed. Belo Horizonte: Editora da UFMG, 2004. p. 20-21.

39 AGAMBEN, Giorgio. Stasis. La guerra civile come paradigma politico. Homo sacer, II, 2. Torino: Bollati Boringhieri, 2015. p. 33-77.

40 AGAMBEN, Giorgio. Stasis. La guerra civile come paradigma politico. Homo sacer, II, 2. Torino: Bollati Boringhieri, 2015. p. 33-77.

41 RIBEIRO, Renato Janine. A marca do Leviatã. Linguagem e poder em Hobbes. 2. ed. São Paulo: Ateliê Editorial, 2003. 
a "fundamentar a autoridade política no conhecimento dos homens e não no direito divino dos reis" 42 . Hobbes foi pioneiro, ao afirmar que o direito constitui-se apenas naquilo que é posto pelo Estado. Esse foi o marco fundador do positivismo jurídico ${ }^{43}$. O brocardo latino tornado célebre por Hobbes - Auctoritas non veritas facit legem - define bem sua convicção quanto às fontes do direito ${ }^{44}$.

Esse é o giro marcante da teoria do direito da época: a afirmação do princípio da legalidade, do direito posto pelo Estado secular como única fonte legislativa. Assim, uma norma não é válida por ser justa ou injusta, mas tão somente por ter sido posta por uma autoridade dotada de competência normativa. A consolidação do princípio da legalidade representou verdadeira revolução nas estruturas da prémodernidade. Pode-se identificar quatro âmbitos de mudanças paradigmáticas nesse positivismo jurídico ainda embrionário: ( $i$ ) na natureza e na estrutura do Direito; (ii) na natureza e no papel da jurisdição; (iii) no estatuto epistemológico da ciência jurídica; e, (iv) por fim, na natureza da filosofia política ${ }^{45}$.

Hobbes é um dos fundadores do contratualismo ${ }^{46}$, pois propõe a união do povo por meio de um pacto social. Uma vez pactuado o acordo que busca fundar uma sociedade estável, não é mais possível a esse mesmo povo voltar atrás e repactuar o que foi anteriormente previsto, uma vez que essa prerrogativa agora é única e exclusiva do monarca soberano. O fiador da segurança e da ordem - da autoridade - é, nessa nova maneira de pensar, o soberano, ao qual foi delegado poder pelos seus súditos. Aqui se encontra o cerne da questão: a autoridade é emanada pelo poder soberano, e é isso que proporciona ordem e unidade por meio da soberania irrevogável ${ }^{47}$.

42 POGREBINSCHI, Thamy. Thomas Hobbes (Verbete). In: BARRETTO, Vicente de Paulo (Org.). Dicionário de Filosofia do Direito. São Leopoldo: Editora Unisinos/Renovar, 2006. p. 436-439.

43 MATTEUCCI, Nicola. Introduzione. In: HOBBES, Thomas. Hobbes. Antologia di scritti a cura di Nicola Matteucci. Bolonha: Il Mulino, 1982. p. 10.

44 HOBBES, Thomas. Leviatã ou Matéria, forma e poder de um estado eclesiástico e civil. Tradução de João Paulo Monteiro e Maria Beatriz Nizza da Silva. 3. ed. São Paulo: Abril Cultural, 1983.

45 FERRAJOLI, Luigi. Principia iuris. Teoria del derecho y de la democracia. 2. Teoria de la democracia. Madrid: Editorial Trotta, 2011. p. 48-49.

46 FERRAJOLI, Luigi. Principia iuris. Teoria del derecho y de la democracia. 2. Teoria de la democracia. Madrid: Editorial Trotta, 2011. p. 48.

47 HOBBES, Thomas. Leviatã ou Matéria, forma e poder de um estado eclesiástico e civil. Tradução de João Paulo Monteiro e Maria Beatriz Nizza da Silva. 3. ed. São Paulo: 
O modelo de Estado Absolutista desenhado por Hobbes proporciona bases sólidas para um sistema de ordem, segurança e paz social que evita a todo custo a guerra civil. Essa construção é a gênese do Estado Moderno. De um modo geral, o contratualismo hobbesiano foi responsável por romper com todas as formas de jusnaturalismo de forma abrupta e pioneira, concebendo o direito apenas como elemento forjado no seio do Estado.

A negação da estrutura da common law é total, chegando a ponto de Hobbes reduzir o modelo tribunalício, arduamente defendido por Sir Edward Coke, a mero jusnaturalismo que conduz inexoravelmente ao estado de natureza ${ }^{48}$. Ao mesmo tempo, o sistema ilustrado por Hobbes é autoritário, centrado na ausência de limites do poder soberano. Essa refundamentação do direito abandona o jusnaturalismo da common law e aceita o princípio da legalidade como metanorma de reconhecimento e garantia de certeza e de liberdade contra arbitrariedades ${ }^{49}$.

As ideias predominantes na Inglaterra da época, frontalmente contrárias a Hobbes, deram origem ao constitucionalismo inglês, personificado e simbolizado pela pessoa de Coke. A ideia de soberania absoluta era incompatível com as convicções do movimento constitucionalista inglês, que propunha um papel relevante para o parlamento e para a tradição judiciária da common law. Essa discussão tornou-se célebre no livro A Dialogue between a Philosopher and a Student of the Common Laws of England ${ }^{50}$, do próprio Thomas Hobbes ${ }^{51}$ :

En efecto, podemos identificar la especificidad del derecho natural y la razón de su persistencia como ideología jurídica dominante hasta em nacimiento del Estado moderno precisamente en la falta de criterios formales y en el carácter inevitablemente sustancial de los criterios de valoración de la validez de las normas fundadas en él. De las dos máximas -auctoritas, non veritas facit legem y veritas, non auctoritas facit legemsostenida una por Thomas Hobbes y la otra atribuida por él gran jurista

Abril Cultural, 1983.

48 FERRAJOLI, Luigi. Principia iuris. Teoria del derecho y de la democracia. 2. Teoria de la democracia. Madrid: Editorial Trotta, 2011. p. 48-49.

49 FERRAJOLI, Luigi. Principia iuris. Teoria del derecho y de la democracia. 2. Teoria de la democracia. Madrid: Editorial Trotta, 2011. p. 32-33.

50 HOBBES, Thomas. A Dialogue between a Philosopher and a Student of the Common Laws of England. Chicago: University of Chicago Press, 2007.

51 BOBBIO, Norberto. Thomas Hobbes. Tradução de Carlos Nélson Coutinho. Rio de Janeiro: Campus, 1991. p. 45-48. 
sir Edward Coke, la que reflejaba el "ser" y a la vez el fundamento de validez del derecho en la experiencia jurídica premoderna era en efecto la segunda; mientras que la primera expresaba, con aparente paradoja; su "deber ser", esto es, una instancia axiológica o filosóficopolítica que se realizará con el nacimiento del Estado moderno como monopolio de la producción jurídica ${ }^{52}$.

Coke afirmava a persistência da tradição da common law e da inevitável valoração substancial das normas, de cunho jusnaturalista, contra a qual Hobbes se insurgia duramente, ao direcionar ao Estado o monopólio da produção jurídica. Apesar de Hobbes prescrever o princípio da legalidade em sua forma mais crua e primitiva, ao mesmo tempo admitia a possibilidade de resultado silentium legis, ou seja, que as liberdades concedidas por lei poderiam sofrer supressões ou reduções de acordo com a vontade soberana. A antítese desse pensamento são as liberdades selvagens, que significavam a ausência do direito. Paradoxalmente, então, verifica-se que as principais teses de Hobbes rompem abruptamente com a tradição constitucionalista britânica ${ }^{53}$.

No plano político, Hobbes defendia, enfaticamente, a soberania do monarca em oposição à dissensão parlamentar - que, para ele, nada mais era que um dos principais combustíveis da anarquia e da desordem e um primeiro passo para o desencadeamento da guerra civil. Não por outra razão contrapôs, como já referido, a alegoria do Leviatã à da figura mitológica Behemoth, ou o Longo Parlamento. A simbologia do Behemoth simboliza a obsessão do filósofo contra as infindáveis discussões da sociedade civil que, para ele, inevitavelmente levam à guerra de todos contra todos. Seu pensamento norteia-se, assim, pela convicção de que, uma vez liberados os debates e as discussões democráticas no seio da sociedade, o dissenso se imporá e serão abertas as portas ao caos. Essa é uma das perspectivas da metáfora do Longo Parlamento ${ }^{54}$.

Hobbes, então, opõe o Behemoth ao Leviatã. A primeira metáfora diz respeito à guerra civil que tudo dilacera e aniquila; enquanto a segunda representa a

52 FERRAJOLI, Luigi. Principia iuris. Teoria del derecho y de la democracia. 1. Teoria del derecho. Madrid: Editorial Trotta, 2007. p. 111.

53 FERRAJOLI, Luigi. Principia iuris. Teoria del derecho y de la democracia. 1. Teoria del derecho. Madrid: Editorial Trotta, 2007. p. 153.

54 HOBBES, Thomas. Behemoth. Madrid: Tecnos, 2013. 
unidade do sistema político e sua capacidade de aglutinar os indivíduos em torno de um soberano por meio do pacto comum. Frise-se que Hobbes vive numa Inglaterra assolada pela guerra civil, onde reina a instabilidade política decorrente, em grande medida, das guerras religiosas. Todo pensamento político hobbesiano gira em torno da obsessão pela ideia da dissolução da autoridade.

Para seguir o objetivo de criar uma estrutura de governo sólida e indissolúvel, é preciso criar, segundo o autor do Leviatã, um Estado secularizado que em nenhum momento se veja em perigo diante da perspectiva de guerra civil. Dessa nefasta guerra interna - fomentada pela anarquia, pelo dissenso e pela pluralidade de opiniões sediciosas - derivam a mortandade, o deserto, a falta de tudo e toda sorte de calamidades.

Hobbes concebia o Estado como instrumento pelo qual seria possível suprir as deficiências, para ele evidentes, da natureza humana. Dito de outra forma, a nascente industriosidade humana alcançada nesse momento histórico seria a chave para se superar o estado de natureza, já que, diferentemente do aristotelismo político, a sociabilidade não é natural, mas artificial. Essa pretensão de criar a máquina, o artificium, permeia toda a sua obra. Denota-se, assim, uma tendência bem definida desse momento do pensamento humano: a vontade quase incontrolável de se fazer ciência, de distinguir os atos humanos como científicos ou a-científicos ${ }^{55}$.

Em um contexto, no qual o homem, pouco a pouco, consegue criar qualquer coisa, inclusive animais artificiais, o Leviatã cria, ao mesmo tempo que domestica, o Estado (ou a Cidade). O Leviatã seria um homem artificial de maior estatura, projetado para a proteção e para a defesa. A soberania, então, seria a sua alma artificial, pois dá vida e movimento para o corpo inteiro ${ }^{56}$.

Para Hobbes, as leis são uma razão e uma vontade artificiais - por serem secularizadas - sujeitas apenas ao poder soberano ilimitado, e não mais à religião ou à moral. Somente o soberano é capaz de evitar a morte de tudo no chamado 55 BOBBIO, Norberto. Thomas Hobbes. Tradução de Carlos Nélson Coutinho. Rio de Janeiro: Campus, 1991. p. 31.

56 HOBBES, Thomas. Leviatã ou Matéria, forma e poder de um estado eclesiástico e civil. Tradução de João Paulo Monteiro e Maria Beatriz Nizza da Silva. 3. ed. São Paulo: Abril Cultural, 1983. p. 5. 
Reino das Trevas. O homem não mais é chamado a imitar a natureza, dentro de suas limitações, e é capaz de corrigir a natureza - e a exteriorização mais elevada dessa qualidade de artífice é a constituição do Estado ${ }^{57}$.

No Leviatã resta nítida a obsessão sobre a titularidade do poder soberano. O filósofo inglês identifica a natureza humana a partir de um viés pessimista antropológico. O homem possuiria, segundo ele, um desejo insaciável de poder e, por isso, estaria demonstrada a miserabilidade da condição humana, razão pela qual é necessário um poder centralizado e soberano, que detenha autoridade, a fim de fazer frente à incessante busca de poder pelos humanos ${ }^{58}$.

Para Bobbio, Hobbes nunca acreditou que o estado de natureza e que o próprio conceito de guerra de todos contra todos fossem um estado de guerra violenta ininterrupta. Nesse ponto, a guerra civil seria caracterizada pelos estabelecimentos de acordos de paz precários, nos quais a calmaria é frágil, sendo assegurada apenas pelo temor recíproco. Nesse contexto, a paz só se torna possível por causa da permanente ameaça de guerra, que é uma situação que perdura até hoje e, atualmente, é chamada usualmente de "dissuasão"59.

A metáfora da guerra do homem contra o homem, do homem como lobo do homem (homo homini lupus), funciona como construção imaginária calcada nas experiências pessoais de Hobbes com a violência civil. $\mathrm{O}$ denominador comum de sua teoria é o medo. Para afastar esse profundo medo, o soberano é chamado para - autoritariamente - trazer e manter a ordem. Essa construção influenciará diversos pensadores séculos mais tarde, como Max Weber e Schumpeter.

O próprio positivismo normativista de Hans Kelsen é profundamente marcado pelo positivismo inaugurado por Hobbes. A preocupação com o rigor no trato da linguagem, tão cara à tradição positivista recente, está presente no pensamento hobbesiano. Nesse momento histórico, a lógica começa a estabelecer conjuntos de expedientes para tornar a linguagem mais rigorosa ${ }^{60}$. Kelsen aponta 57 BOBBIO, Norberto. Thomas Hobbes. Tradução de Carlos Nélson Coutinho. Rio de Janeiro: Campus, 1991. p. 33.

58 BOBBIO, Norberto. Thomas Hobbes. Tradução de Carlos Nélson Coutinho. Rio de Janeiro: Campus, 1991. p. 35.

59 BOBBIO, Norberto. Thomas Hobbes. Tradução de Carlos Nélson Coutinho. Rio de Janeiro: Campus, 1991. p. 36-37.

60 BOBBIO, Norberto. Thomas Hobbes. Tradução de Carlos Nélson Coutinho. Rio de Janeiro: 
expressamente Hobbes como um dos primeiros filósofos do direito a construir uma teoria do positivismo jurídico, ainda que com o verniz de uma "teologia civil inglesa", com o uso da terminologia do direito natural típica de seu tempo. Nos moldes referidos anteriormente, existe um elo entre esses dois pensadores essencialmente positivistas no que se refere às suas construções teóricas. Os conceitos de soberania, estado e direito de Hobbes influenciarão, de modo determinante, a evolução e o desenvolvimento da teoria kelseniana ${ }^{61}$.

Essa é, muito resumidamente, a gênese do estado moderno que foi legado à contemporaneidade: a submissão do indivíduo ao Leviatã, em troca do estabelecimento de um sistema que proporcionará segurança, ordem e paz ${ }^{62}$.

\section{CONSIDERAÇÕES FINAIS}

A inestimável contribuição de Hobbes à autonomia do direito pode ser sintetizada em sua ode ao direito secularizado, não mais submisso à religião, à moral ou ao jusnaturalismo da common law. O filósofo político alemão Wolfgang Kersting expressa magistralmente a novidade do pensamento hobbesiano, contrapondo-o ao aristotelismo político. Segundo Kersting, o grande mérito da filosofia política de Hobbes está no fato de que, pela primeira vez na história, um Estado tenha a pretensão de contar com o consentimento geral por meio do distanciamento das posições morais, religiosas e ideológicas:

(..) culmina numa concepção de política estatal que, pela primeira vez na história, confia a criação de ordem, consideravelmente dificultada pelo pluralismo ideológico, moral e confessional, a uma política de neutralização e abstinência em relação à verdade: só um Estado que renuncia ele próprio à verdade, que permanece na eqüidistância neutra para com todas as posições morais, religiosas e ideológicas, pode levantar a pretensão de contar com o consentimento geral63.

Campus, 1991. p. 32.

61 KELSEN, Hans. Religione secolare. Una polemica contro l'errata interpretazione della filosofia sociale, della scienza e della politica moderne como "nuove religioni". Milano: Raffaello Cortina Editore, 2014. p. 113-115.

62 ZOLO, Danilo. Sulla paura. Fragilità, agressività, potere. Milano: Feltrinelli, 2011. p. 50-58.

63 KERSTING, Wolfgang. Universalismo e direitos humanos. Porto Alegre: Edipucrs, 2003. p. 71. 
Essa consolidação do princípio da legalidade no positivismo hobbesiano gerou mudanças paradigmáticas, impondo uma nova estrutura epistemológica do direito, na ciência jurídica e na filosofia política ${ }^{64}$. No momento em que o direito posto pelo Estado se apresenta como única fonte legislativa, a normatização religiosa deixa de ter importância. O Estado concebido por Hobbes funda-se na autoridade soberana e na competência normativa, diminuindo a força das ordens normativas pautadas pela religião, como efetivamente se verificou com o gradual esvaziamento do Direito Canônico em todos os países Ocidentais com o passar dos séculos.

\section{REFERÊNCIAS}

AGAMBEN, Giorgio. Stasis. La guerra civile come paradigma politico. Homo sacer, II, 2. Torino: Bollati Boringhieri, 2015. p. 33-77.

BERMAN, Harold J. Direito e revolução. A formação da tradição jurídica ocidental. São Leopoldo: Editora da Unisinos, 2004.

$\mathrm{BLOCH}$, Marc. Os reis taumaturgos. O poder sobrenatural do poder régio. França e Inglaterra. São Paulo Companhia das Letras, 1993.

BLUMENBERG, Hans. Säkularisierung und Selbstbehauptung [Secularização e autoafirmação]. Frankfurt am Main: Suhrkamp, 1974.

BLUMENBERG, Hans. Die Legimität der Neuzeit [A legitimidade da modernidade]. 3. Aufl. Frankfurt am Main: Suhrkamp, 1985.

BLUMENBERG, Hans; SCHMITT, Carl. L'enigma della modernità. Roma-Bari: Laterza, 2012. p. 4-18.

BOBBIO, Norberto. Thomas Hobbes. Tradução de Carlos Nélson Coutinho. Rio de Janeiro: Campus, 1991. p. 27 e 56-60.

BÖCKENFÖRDE, Ernst-Wolfgang. Recht, Staat, Freiheit: Studien zur Rechtsphilosophie, Staatstheorie und Verfassungsgeschichte [Direito, Estado, liberdade: estudos sobre a filosofia do direito, teoria do Estado e história da constituição]. Frankfurt am Main: Suhrkamp, 2006. $425 \mathrm{p}$.

64 FERRAJOLI, Luigi. Principia iuris. Teoria del derecho y de la democracia. 2. Teoria de la democracia. Madrid: Editorial Trotta, 2011. p. 48-49. 
BULYGIN, Eugenio. Il positivismo giuridico. Tradução de Cosimo Marco Mazzoni e Vincenzo Varano. Milão: Giuffrè Editore, 2007.

FERRAJOLI, Luigi. Principia iuris. Teoria del derecho y de la democracia. 2. Teoria de la democracia. Madrid: Editorial Trotta, 2011.

FERRAJOLI, Luigi. Principia iuris. Teoria del derecho y de la democracia. 1. Teoria del derecho. Madrid: Editorial Trotta, 2007.

HABERMAS, Jürgen. Fé e saber. São Paulo: Editora Unesp, 2013.

HALDEMANN, Frank. Gustav Radbruch v. Hans Kelsen: um debate sobre o Direito Nazista. In: FARO, Júlio Pinheiro; BUSSINGER, Elda Coelho de Azevedo (Orgs.). A diversidade do pensamento de Hans Kelsen. Rio de Janeiro: Lumen Juris, 2011. p. 275-294.

HOBBES, Thomas. Leviatã ou Matéria, forma e poder de um estado eclesiástico e civil. Tradução de João Paulo Monteiro e Maria Beatriz Nizza da Silva. 3. ed. São Paulo: Abril Cultural, 1983.

HOBBES, Thomas. A Dialogue between a Philosopher and a Student of the Common Laws of England. Chicago: University of Chicago Press, 2007.

KERSTING, Wolfgang. Universalismo e direitos humanos. Porto Alegre: Edipucrs, 2003.

LIMA VAZ, Henrique Cláudio de. As raízes da modernidade. Escritos de Filosofia VII. São Paulo: Loyola, 2002.

MARRAMAO, Giacomo. Céu e terra: genealogia da secularização. Tradução de Guilherme Alberto Gomez de Andrade. São Paulo: Fundação Editora da UNESP, 1997.

MARTÍNEZ, Gregório Peces-Barba. Trânsito a la modernidad y derechos fundamentales. In: MARTÍNEZ, Gregório Peces-Barca; GARCIA, Eusebio Fernandez. História de los derechos fundamentales. T. I. Transito a la modernidad. Siglos XVI y XVII. Madrid: Dykinson, 2003. p. 29-88.

MATTEUCCI, Nicola. Introduzione. In: HOBBES, Thomas. Hobbes. Antologia di scritti a cura di Nicola Matteucci. Bolonha: Il Mulino, 1982.

KELSEN, Hans. Religione secolare. Una polemica contro l'errata interpretazione della filosofia sociale, della scienza e della politica moderne como "nuove religioni". Milano: Raffaello Cortina Editore, 2014. 
KELSEN, Hans. Il problema della sovranità. Milão: Giuffrè Editore, 1989.

KOSELLECK, Reinhart. Estratos do tempo: estudos sobre história. Tradução de Markus Hediger. 1. ed. Rio de Janeiro: Contraponto/PUC-Rio, 2014.

LOSANO, Mário G. Sistema e estrutura no direito. Volume 2: o século XX. Tradução de Luca Lamberti. São Paulo: Editora WMF Martins Fontes, 2010.

MONEREO PÉREZ, José Luis. Los fundamentos de la democracia. La teoría politico jurídica de Hans Kelsen. Barcelona: El Viejo Topo, 2013.

NEVES, A. Castanheira. Digesta. Escritos acerca do direito, do pensamento jurídico, da sua metodologia e outros. v. $2^{\circ}$. Coimbra: Wolters Kluwer/Coimbra Editora, 2010.

OST, François; KERCHOVE, Michel van de. De la pyramide au réseau? Pour un théorie dialectique du droit. Bruxelas: Publications des Facultés Universitaires Saint-Louis, 2002.

POGREBINSCHI, Thamy. Thomas Hobbes (Verbete). In: BARRETTO, Vicente de Paulo (Org.). Dicionário de Filosofia do Direito. São Leopoldo: Editora Unisinos/Renovar, 2006. p. 436439.

SCHMITT, Carl. Politische Theologie [Teologia política]. Vier Kapitel zur Lehre von der Souveranität. 2. Aufl. Berlin: Duncker, 1984.

SCHMITT, Carl. Teología política. Tradução de Francisco Javier Conde. Madrid: Editorial Trotta, 2009.

STRECK, Lenio Luiz. Lições de crítica hermenêutica do direito. Porto Alegre: Livraria do Advogado, 2014.

TROELTSCH, Ernst. Protestantisme et modernité. Tradução de Marc B. de Launay. Paris: Éditions Gallimard, 1991.

WOOTTON, David. Divine right and democracy. An anthology of political writings in Stuart England. London: Penguis Classics, 1986.

ZOLO, Danilo. Sulla paura. Fragilità, agressività, potere. Milano: Feltrinelli, 2011.

Recebido em: out/2015

Aprovado em: dez/2015 